\title{
Guided wave observations and evidence for the low-velocity subducting crust beneath Hokkaido, northern Japan
}

\author{
Takahiro Shiina*, Junichi Nakajima, Genti Toyokuni and Toru Matsuzawa
}

\begin{abstract}
At the western side of the Hidaka Mountain range in Hokkaido, we identify a clear later phase in seismograms for earthquakes occurring at the uppermost part of the Pacific slab beneath the eastern Hokkaido. The later phase is observed after P-wave arrivals and has a larger amplitude than the P wave. In this study, we investigate the origin of the later phase from seismic wave observations and two-dimensional numerical modeling of wave fields and interpret it as a guided $\mathrm{P}$ wave propagating in the low-velocity subducting crust of the Pacific plate. In addition, the results of our numerical modeling suggest that the low-velocity subducting crust is in contact with a low-velocity material beneath the Hidaka Mountain range. Based on our interpretation for the later phase, we estimate P-wave velocity in the subducting crust beneath the eastern part of Hokkaido by using the differences in the later phase travel times and obtain velocities of 6.8 to $7.5 \mathrm{~km} / \mathrm{s}$ at depths of 50 to $80 \mathrm{~km}$. The obtained P-wave velocity is lower than the expected value based on fully hydrated mid-ocean ridge basalt (MORB) materials, suggesting that hydrous minerals are hosted in the subducting crust and aqueous fluids may co-exist down to depths of at least $80 \mathrm{~km}$.
\end{abstract}

Keywords: Guided wave; Subducting crust; Pacific slab; Hokkaido; Finite difference method; Dehydration; Intermediate-depth earthquake

\section{Findings}

\section{Introduction}

The subducting crust at the uppermost part of the oceanic lithosphere is considered to play important roles in fluid circulation in subduction zones because the crust contains a large amount of water in the form of hydrous minerals (e.g., Hacker et al. 2003). Aqueous fluids and volatiles released by dehydration of hydrous minerals contribute to the genesis of intraslab earthquakes (e.g., Kirby et al. 1996) and arc magmatism (e.g., Nakajima et al. 2013).

In cold subduction zones, the subducting crust has been imaged as a low-velocity and high- $V \mathrm{p} / V \mathrm{~s}$ layer at depths of $<100 \mathrm{~km}$ in which the seismic velocity increases at greater depths (e.g., Ferris et al. 2003; Kawakatsu and Watada 2007; Nakajima et al. 2009a). The increase in velocity in the crust appears to be correlated with an abrupt decrease in seismic activity beyond a depth range of the upper plane seismic belt that is defined as a concentrated

\footnotetext{
* Correspondence: shina@aob.gp.tohoku.ac.jp

Research Center for Prediction of Earthquakes and Volcanic Eruptions, Graduate School of Science, Tohoku University, Sendai 980-8578, Japan
}

crustal seismicity at depths of 70 to $90 \mathrm{~km}$ (Kita et al. 2006). This phenomenon suggests that earthquakes in the crust are facilitated as a result of substantial pore fluid generated by dehydration reactions to eclogite from hydrous minerals (e.g., Abers et al. 2013). Therefore, investigations of the locations of which hydrous minerals are hosted and dehydration reaction occurs are important for understanding ongoing metamorphism and the resultant processes in subduction zones.

Later phases are often observed in seismograms of intraslab earthquakes (e.g., Hori et al. 1985; Abers et al. 2003; Furumura and Kennett 2005). A P-to-S converted wave (PS wave) at the slab interface is one of the distinct later phases sensitive to heterogeneity in the subducting crust (Matsuzawa et al. 1986). Shiina et al. (2013) estimated P-wave velocity in the crust of the Pacific slab beneath northeastern Japan by the inversion of the arrival time of PS waves and suggested that aqueous fluids co-exist with hydrous minerals at depths of 60 to $90 \mathrm{~km}$. Another indication of marked later phases is the presence of guided waves trapped in the low-velocity subducting crust (e.g., 
Hori et al. 1985; Abers 2005). Guided waves are much more sensitive to the crustal structure because of their longer propagation paths in the crust; hence, they are very useful for estimating seismic velocity in the crust. Guided waves can be efficiently observed in the subducting crust in contact with the continental crust (e.g., Martin et al. 2005; Miyoshi et al. 2012) and can also occur due to bending of the slab (e.g., Martin and Rietbrock 2006).

In this study, we identify later phases in seismograms of intraslab earthquakes at stations located around the Hidaka Mountain range in Hokkaido, northern Japan (Figure 1). We investigate the origin of the later phases with numerical modeling and interpret them as guided waves that are produced in the subducting crust. Finally, we estimate P-wave velocity in the crust using arrival times of the later phase.

\section{Observations of prominent later phases}

Seismograms recorded in and around the Hidaka Mountain range in the middle of Hokkaido show different features from those observed in its western and eastern sides in terms of amplitude and frequency components of the initial P and S waves (e.g., Furumura and Moriya 1990). In this region, the arc-arc collision between the Kuril and northeastern Japan arcs is ongoing (e.g., Kimura 1996), and the structure is highly complex (e.g., Iwasaki et al. 2004; Kita et al. 2012).

We frequently observed marked later phases in seismograms of intraslab earthquakes recorded on the western side of the Hidaka Mountain range, which are considered to be closely linked to the complex structure. Characteristics of the later phases, herein referred to as the ' $\mathrm{X}$ phase', are summarized in the following points:

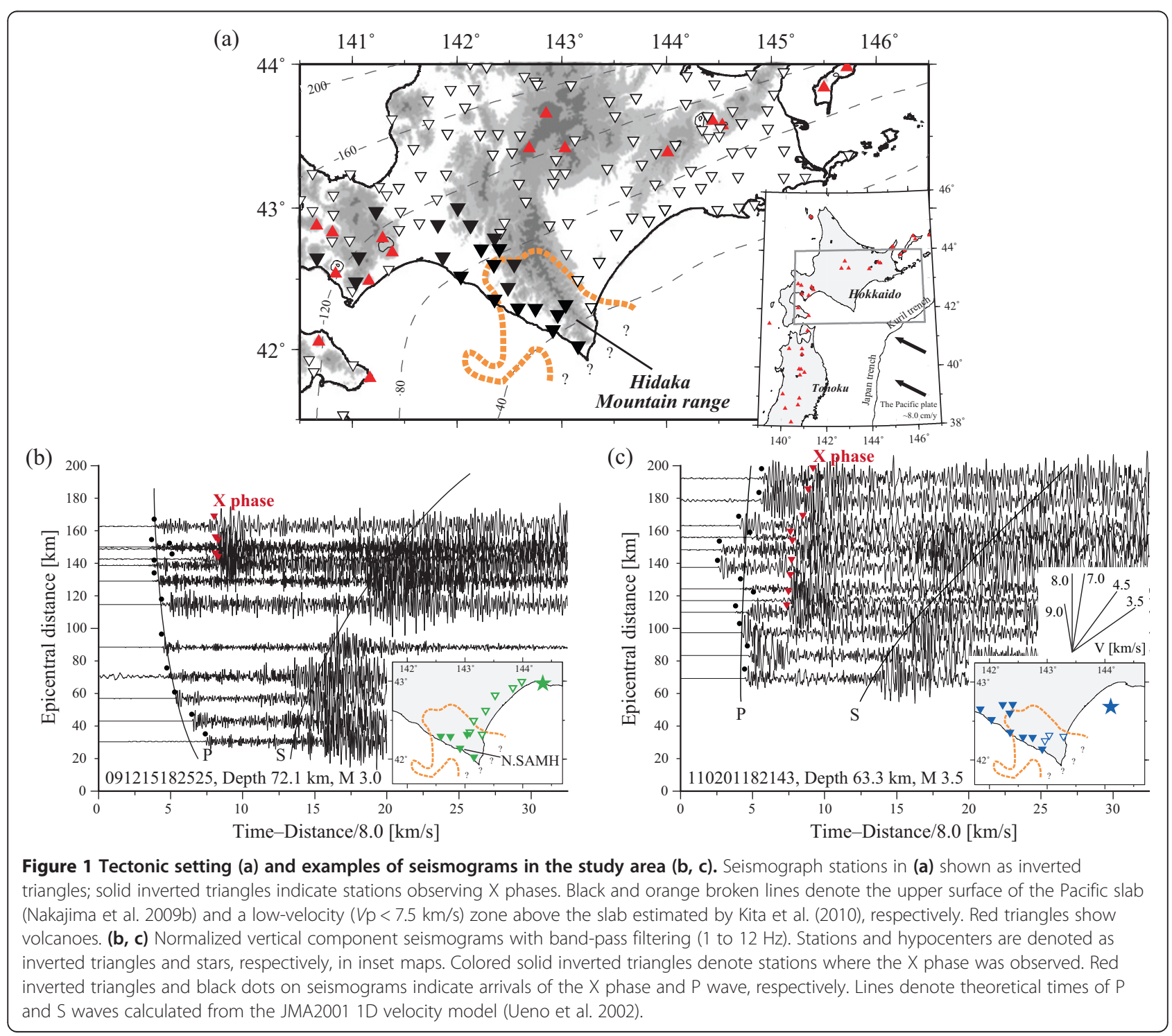


1. The X phase is observed between $\mathrm{P}$ - and S-wave arrivals, and the apparent velocity is almost the same as that of the $\mathrm{P}$ wave (Figure $1 \mathrm{~b}, \mathrm{c}$ ).

2. Amplitudes of the $X$ phase are similar to or larger than those of the $\mathrm{P}$ wave (Figures 1 and 2).

3. The $\mathrm{X}$ phase is dominantly observed in the vertical component and arrives at a station as a $\mathrm{P}$ wave (Figure 2).

4. The arrival time difference between the $X$ phase and the $\mathrm{P}$ wave (X-P time) is 2 to $10 \mathrm{~s}$, which increases with epicentral distance (Figure 3 ).

5. The X phase is mainly observed at stations located on the western side of the Hidaka Mountain range for earthquakes occurring at the upper surface of the Pacific slab beneath the eastern part of Hokkaido (Figure 4).

Shimizu and Maeda (1980) reported later phases that have characteristics similar to those of the $\mathrm{X}$ phase, and they concluded that the later phases were generated by a P-to-P reflection at an inclined reflector beneath the Hidaka Mountain range. As a benefit of the nationwide dense seismograph network in Japan, we can observe the $\mathrm{X}$ phase at stations distributed in a wider area than that in Shimizu and Maeda (1980). The X phase is difficult to interpret as a P-to-P reflection wave at the reflector proposed by Shimizu and Maeda (1980), but it is attributable to highly heterogeneous structures in the Pacific slab.

One possible origin of the $\mathrm{X}$ phase is a mode-converted wave at velocity discontinuities between the source and receiver. If we assume the $\mathrm{X}$ phase to be an S-to-P converted wave (SP wave) at the Pacific slab interface, the time difference between SP and P waves is 1 to $4 \mathrm{~s}$, which increases with epicentral distance (gray-shaded area in Figure 3). These time differences are too small to explain the characteristics of the $\mathrm{X}$ phase, such as characteristics 1 and 4 . listed above. Therefore, we excluded the SP wave from the Pacific slab interface in the origin of the $\mathrm{X}$ phase. If we assume that the $\mathrm{X}$ phase is an SP wave from the continental Conrad or Moho, the phase should be observed only at stations near the epicenter because the incident angle to the discontinuities must be less than the critical angle for $\mathrm{SP}$ conversion. This contradicts the observation that the $\mathrm{X}$ phase appears only at stations with large epicentral distances (Figure 1); hence, the SP wave at either the Conrad or Moho is not a plausible candidate for the origin of the $\mathrm{X}$ phase.

Guided waves are known to be generated in the lowvelocity subducting crust when earthquakes occur in or immediately below the crust (e.g., Martin et al. 2003; Miyoshi et al. 2012). Time differences between guided and initial waves increase with propagation distance in the subducting crust (e.g., Ohkura 2000). Because the seismic energy is efficiently trapped in the crust when an earthquake is located in the low-velocity crust, the guided $\mathrm{P}$ wave shows a larger amplitude than the $\mathrm{P}$ wave and dominates in the vertical component (e.g., Martin and Rietbrock 2006). Therefore, guided $\mathrm{P}$ waves in the subducting crust can explain observed characteristics 2, 3, and 4 . Amplitudes observed for the $\mathrm{X}$ phase are dominant in frequencies of 2 to $4 \mathrm{~Hz}$; this frequency range is comparable to that observed for guided waves of the subducting crust in other subduction zones (e.g., Martine et al. 2003). The existence of a serpentinized layer in the Pacific slab mantle (Garth and Rietbrock 2014) is a plausible candidate for the origin of the $\mathrm{X}$ phase when earthquakes occur in the mantle. However, the earthquakes for which we observe guided waves are mostly located at the uppermost part of the Pacific slab (Figure 4 and characteristic 5). On the basis of these observations, we consider that guided $\mathrm{P}$ waves generated in the low-velocity subducting crust create the $\mathrm{X}$ phase.

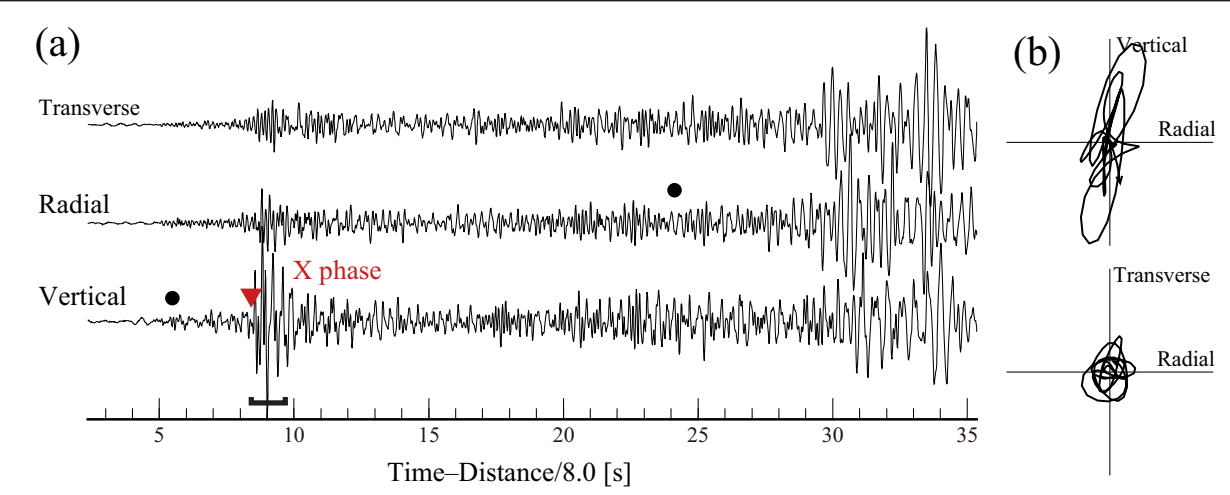

Figure $\mathbf{2}$ Three-component seismograms (a) and particle orbits of the $\mathbf{X}$ phase (b). The station (N.SAMH) and the earthquake are shown in Figure $1 \mathrm{~b}$. Seismograms are band-pass-filtered $(1$ to $12 \mathrm{~Hz}$ ). Black circles denote the theoretical time of $\mathrm{P}$ and $\mathrm{S}$ waves. The red inverted triangle indicates the arrival of the $X$ phase. 


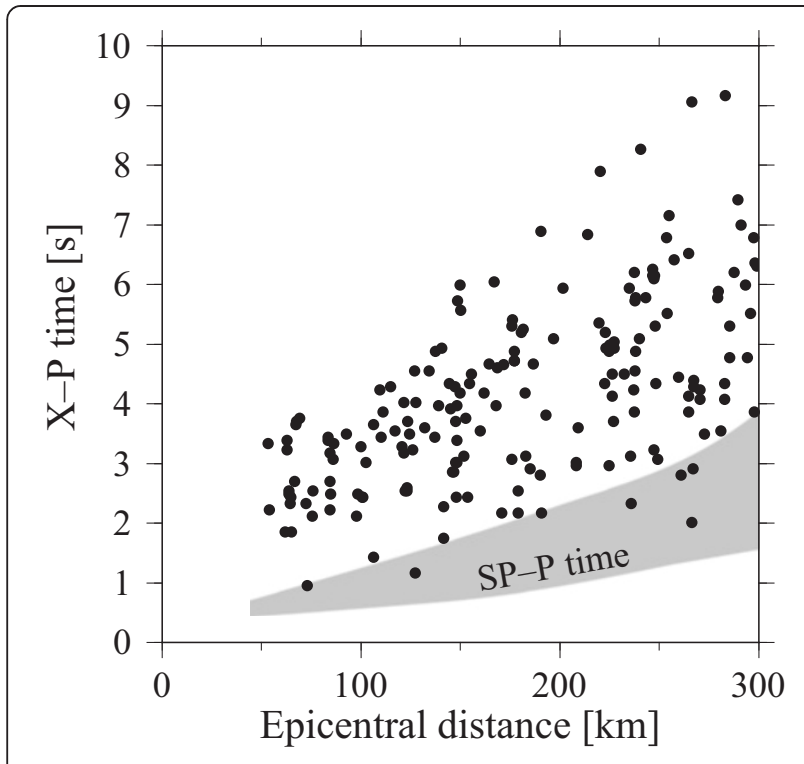

Figure 3 Arrival time differences between the $X$ phase and the $\mathbf{P}$ wave (X-P time). Black dots show observed X-P times. The gray-shaded zone indicates synthetic travel time differences between the P wave and the SP wave at the upper surface of the Pacific slab.

\section{Numerical modeling \\ Model setting}

In this section, we perform numerical modeling of seismic wave propagations and discuss the origin of the $\mathrm{X}$ phase. We calculated the P-SV wave fields for intraslab earthquakes by using a two-dimensional (2D) staggeredgrid finite difference method (e.g., Virieux 1986). The 2D model space is defined on 10,000 grid points in the horizontal direction and 4,000 grids in the vertical direction with a regular grid spacing of $0.05 \mathrm{~km}$. We constructed five-layered models divided by the continental Conrad and Moho (Katsumata 2010), the upper surface of the Pacific slab (Nakajima et al. 2009), and the slab Moho. The P-wave velocity and density in each layer were assumed to be constant, and the values were obtained from the JMA2001 one-dimensional (1D) velocity model (Ueno et al. 2002) and recent tomographic results (e.g., Kita et al. 2010) (Table 1 ). A constant $V \mathrm{p} / V \mathrm{~s}$ ratio of 1.73 (Reynard and Bass 2014) was assumed for the entire model space. It is noted that we conducted modeling for a $V \mathrm{p} / V \mathrm{~s}$ range of 1.70 to 1.90 and confirmed that the amplitude of the guided $\mathrm{P}$ wave is not sensitive to the $V \mathrm{p} / V \mathrm{~s}$. These conditions enabled numerical simulations to be modeled up to a maximum frequency of $8 \mathrm{~Hz}$. We simulated a total duration of $60.0 \mathrm{~s}$ after excitation with a time increment of $0.002 \mathrm{~s}$. For the source time function, we assumed an isotropic point source located in the subducting crust and a Gaussian pulse with a dominant frequency of $3 \mathrm{~Hz}$.

We evaluated wave fields in a sub-parallel profile to the trench axis because Shimizu and Maeda (1980) concluded

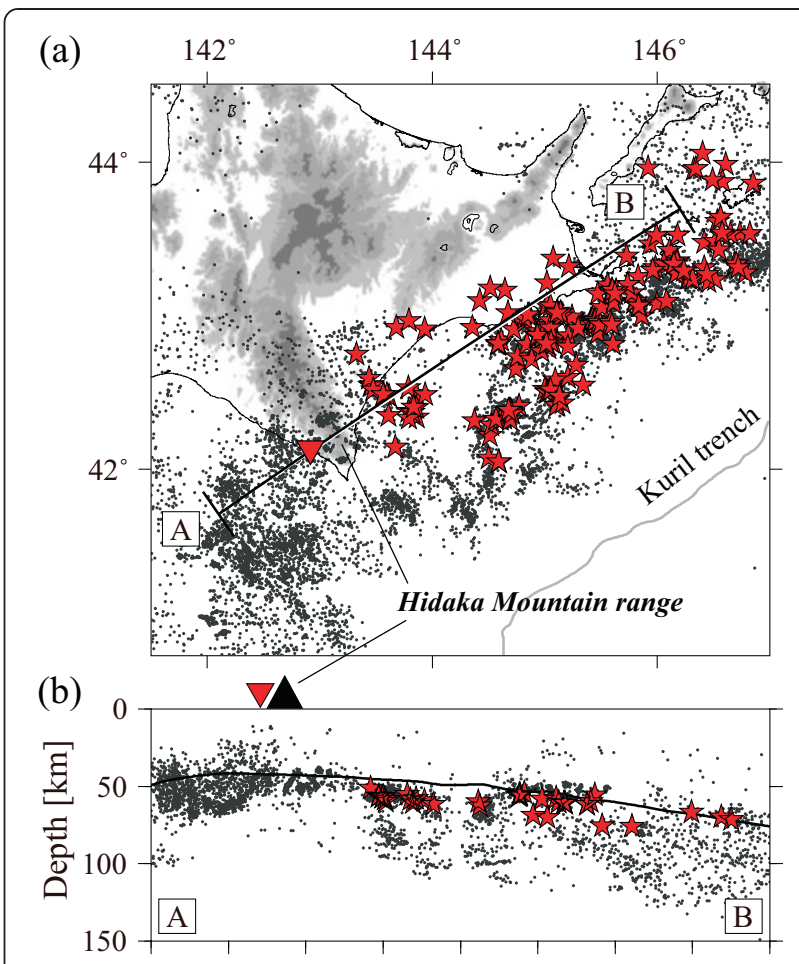

Figure 4 Map (a) and vertical cross-sectional views (b) of hypocenters for $\mathbf{X}$ phases. Station N.SAMH and hypocenters are plotted as red inverted triangle and stars, respectively. Dots in (a) denote background seismicity in the subducting crust. Seismicity within $10 \mathrm{~km}$ from line A-B is shown in (b). The black line in (b) shows the upper surface of the Pacific slab (Nakajima et al. 2009b).

that both $\mathrm{P}$ and $\mathrm{X}$ phases propagate in the same great circle. Because the geometries of the Pacific slab and seismic velocities vary in the subduction direction perpendicular to the assumed profile, an energy leak to a third dimension likely occurs. However, in this study, we focused on only the relative amplitude and time difference of the initial $\mathrm{P}$ and guided waves and do not evaluate the absolute amplitude because the effects of this three-dimensional (3D) structure would be small. However, waveform modeling for a realistic 3D model is an important subject for future study.

Table 1 Model parameters used in numerical modeling

\begin{tabular}{lcc}
\hline & P-wave velocity $[\mathbf{k m} / \mathbf{s}]$ & Density $\left[\mathbf{1 0}^{\mathbf{3}} \mathbf{~} \mathbf{g} / \mathbf{m}^{\mathbf{3}}\right]$ \\
\hline Upper crust & 6.3 & 2.4 \\
Lower crust & 6.7 & 2.8 \\
Mantle wedge & 7.8 & 3.2 \\
Subducting crust & 7.0 & 3.2 \\
Slab mantle & 8.5 & 3.2 \\
\hline
\end{tabular}

Vp/Vs sets are 1.73 for all layers. 

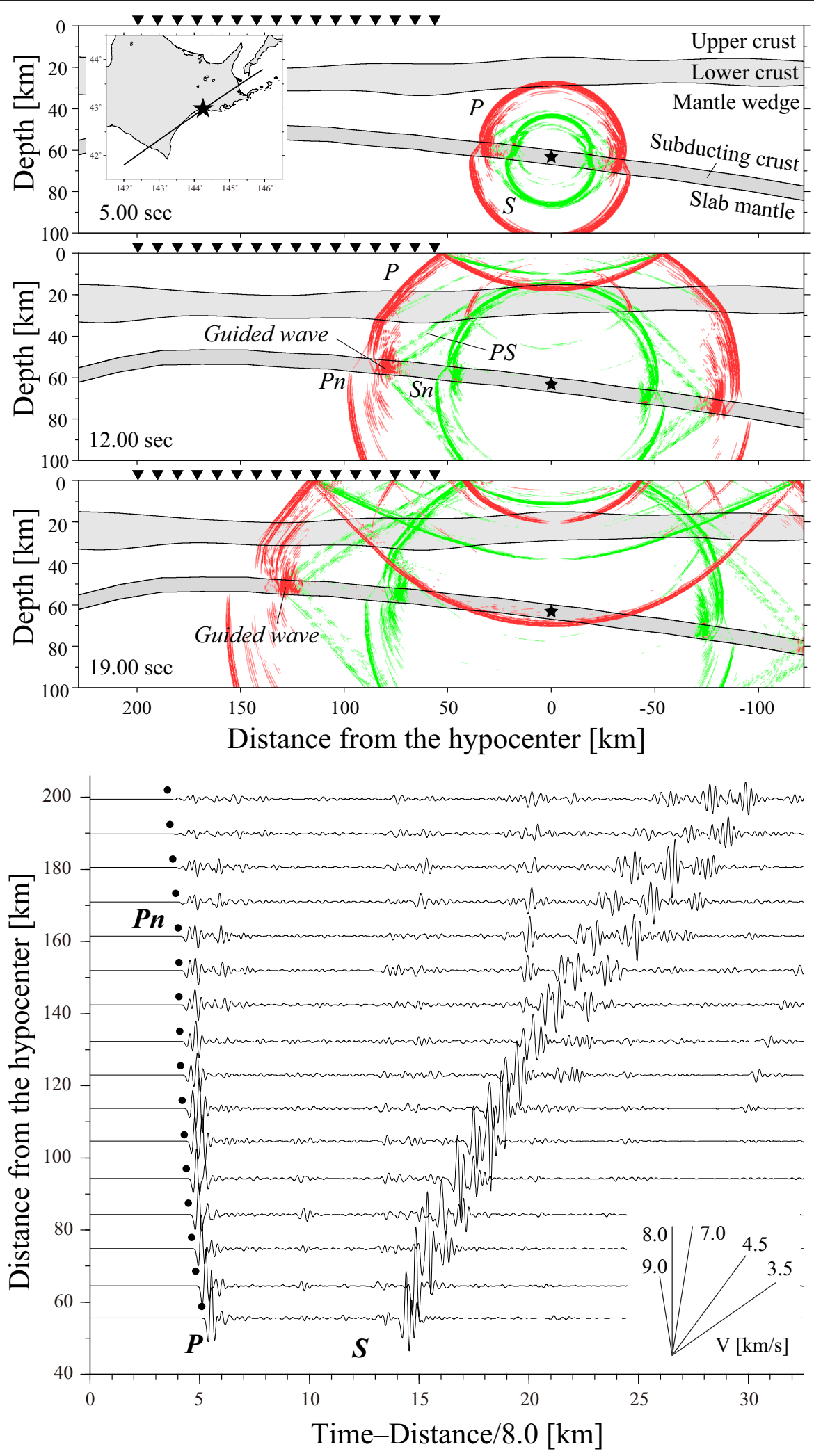

Figure 5 (See legend on next page.) 


\section{Results and discussion}

In the waveform calculations, we considered two velocity models: a standard model with only the low-velocity subducting crust and a model that additionally involves thick low-velocity materials overlying the Pacific slab based on the result of Kita et al. (2010, 2012).

The results for the standard model are shown in Figure 5. At stations near the epicenter, the direct waves arrive as initial P waves, whereas Pn waves refracted at the slab Moho arrive as initial waves at stations located at epicentral distances of more than $160 \mathrm{~km}$. A guided wave is generated and propagated in the subducting crust, as clearly shown in Figure 5 at 12.0 and $19.0 \mathrm{~s}$. A small amount of energy is leaked from the crust as a result of the bending of the subducting plate (e.g., Martin and Rietbrock 2006), as calculated at stations with distances $>140 \mathrm{~km}$, where small phases arrive immediately after P-wave arrivals (Figure 5). However, the energy leakage due to the curvature effect is small, and the later phases do not reproduce with large amplitudes. This result indicates that the energy is not leaked efficiently into the overlying plate in this case; therefore, the standard model cannot explain the observations.

We introduced a low-velocity zone in the overlying continental plate to the standard model at epicentral distances of 75 to $180 \mathrm{~km}$, based on high-resolved velocity structures reported by Kita et al. (2010, 2012). The low-velocity zone is in contact with the subducting crust and has the same velocity as the lower crust (Figure 6). Near the epicenter, simulated wave fields are the same as those obtained with the standard model. However, substantial differences clearly appear at distances $>140 \mathrm{~km}$, where later phases are reproduced clearly after $\mathrm{P}$ waves. Our calculation suggests that the energy trapped in the subducting crust is leaked to the overlaying continental plate as a result of the contact of the subducting crust with the overlying low-velocity zone, as shown in Figure 6 at 19.0 s. The leaked guided waves appear as waveforms, as shown after the red dashed line in the figure.

The numerical simulation for the velocity model with the deepened low-velocity zone indicated that guided waves arrive at stations 2 to $4 \mathrm{~s}$ after $\mathrm{P}$ waves with apparent velocities similar to $\mathrm{P}$ waves. These results explain characteristic 1 . Additionally, our results suggest that the contact of the subducting crust with the overlying lowvelocity material significantly contributes to release the energy trapped in the subducting crust. Marked X phases observed in a wide area of the western side of the Hidaka
Mountain range, as summarized in characteristic 5, are explained by a wide extent of the contact zone.

We interpret the $\mathrm{X}$ phase as a guided $\mathrm{P}$ wave generated in the low-velocity subducting crust because the characteristics of the $\mathrm{X}$ phase can be explained by the propagation of guided waves in the crust. Our interpretations support the results of seismic tomography by Kita et al. $(2010,2012)$ and provide important and independent evidence for the existence of the low-velocity material overlying the subducting crust beneath the Hidaka Mountain range.

\section{P-wave velocity in the subducting crust}

Based on our interpretation, we estimated P-wave velocity in the subducting crust beneath the eastern part of Hokkaido by using arrival times of the guided wave. Because the energy trapped in the curst is efficiently leaked at areas in which the crust is in contact with the overlying low-velocity material, propagation paths from the slab interface to each station are believed to be almost the same for available earthquakes. Therefore, we can estimate P-wave velocity in the crust, assuming that travel time differences of guided waves between a pair of earthquakes with the same back azimuth represent P-wave travel time in the crust between the earthquake pairs. Under this assumption, P-wave velocity of the subducting crust between a pair of earthquakes can be calculated as

$$
V \mathrm{p}=\frac{L}{\Delta t_{\mathrm{X}}},
$$

where $V \mathrm{p}$ is the $\mathrm{P}$-wave velocity in the subducting crust, $L$ is the inter-event distance, and $\Delta t_{\mathrm{X}}$ is the travel time difference of $X$ phases at common stations. We assume that all earthquakes analyzed in this study are located in the subducting crust. Because errors in picking $\mathrm{X}$ phases and in the origin time are both $0.1 \sim 0.3 \mathrm{~s}$ and errors in hypocenters are generally 2 to $4 \mathrm{~km}$, we used only earthquake pairs with inter-event distances $>100 \mathrm{~km}$ and back azimuthal differences $<10^{\circ}$ to make the effect of possible errors on the estimates of P-wave velocity as small as possible. Hence, possible errors included in observations are equivalent to errors of travel times $<1 \mathrm{~s}$, which results in $5 \%$ estimation error of seismic velocity.

From 186 pairs of earthquakes at four stations, the Pwave velocity in the subducting crust was estimated at depths of 50 to $100 \mathrm{~km}$ (Figure 7). The velocity obtained 

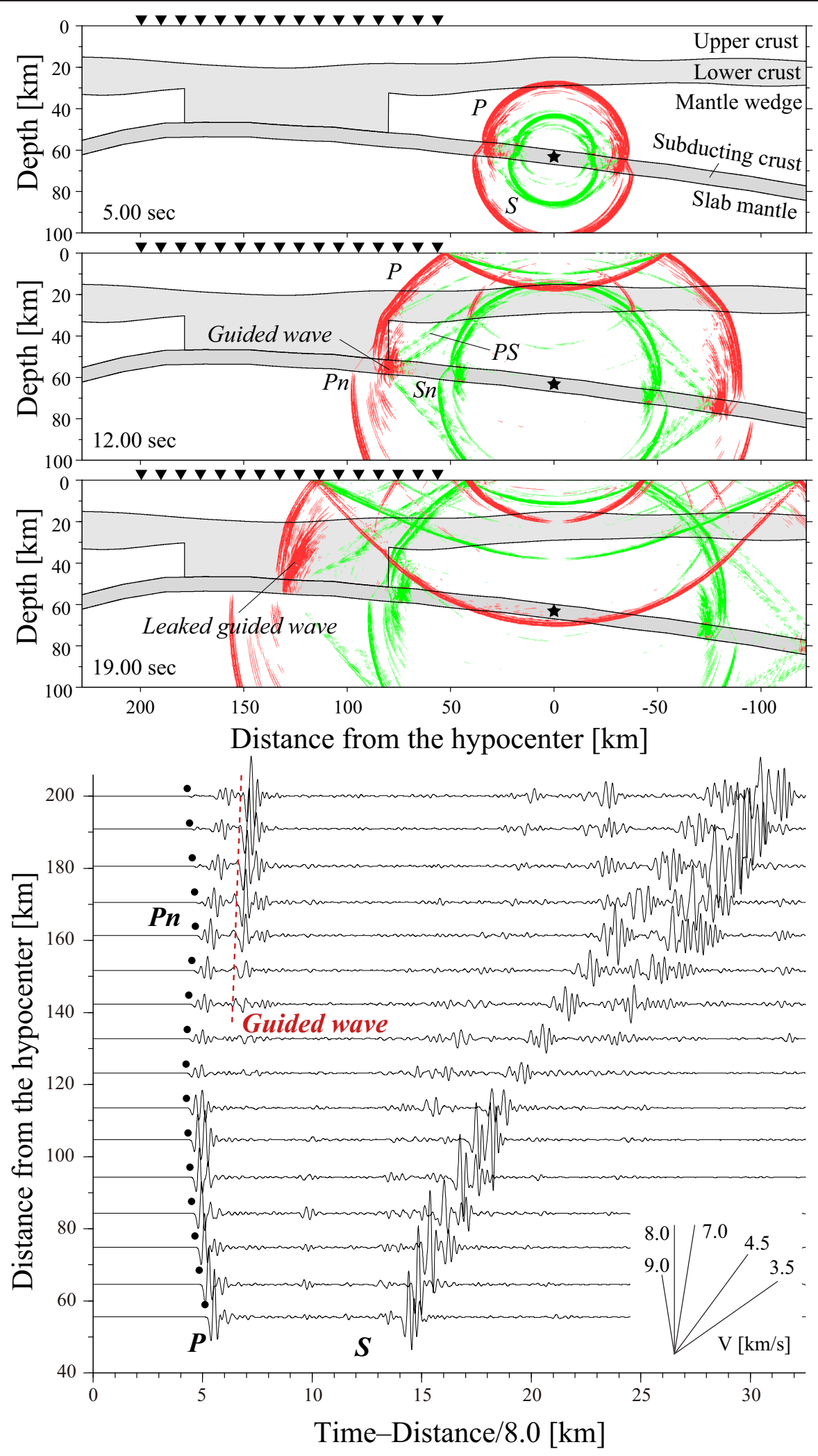

Figure 6 Numerical modeling results for the standard model with the low-velocity material overlying the Pacific slab. (top) Snapshots of seismic wave propagation at 5.0, 12.0, and 19.0 s. (bottom) Simulated vertical component waveforms with a low-pass filter ( $8 \mathrm{~Hz}$ ). Waveforms are scaled by the same amplitude. The red dashed line indicates arrival times of guided waves in the subducting crust. Other symbols are the same as those in Figure 5. 
for a pair of earthquakes was considered as a velocity at an average depth of two earthquakes. The velocities estimated for all available pairs were averaged at every 10 $\mathrm{km}$ depth slice, and velocities of 6.8 to $7.7 \mathrm{~km} / \mathrm{s}$ were obtained (Figure $7 \mathrm{~b}$ ). The P-wave velocities were lower than those in the surrounding mantle $(8 \mathrm{~km} / \mathrm{s})$ and almost agreed with those estimated from the dispersion of guided waves $(7.4 \mathrm{~km} / \mathrm{s}$; Abers 2005). At depths $<80$ $\mathrm{km}$, the obtained P-wave velocities marked lower than the expected values for hydrated compositions of the subducting crust $(7.4 \mathrm{~km} / \mathrm{s}$ for mid-ocean ridge basalt (MORB) and gabbro; Hacker et al. 2003).

The observed velocity may have been affected by anisotropy due to normal faulting formed at the trench outer slope (e.g., Faccenda et al. 2008) because guided waves tend to propagate sub-parallel to strikes of faults. This effect would yield an apparent high velocity of the subducting crust; however, it is difficult to evaluate the effect of anisotropy at present because the geometries and densities of faults are poorly understood. A sedimentary layer located at the top of the subducting slab (e.g., Horleston and Hellfrich 2012) would result in an apparent low velocity of the crust because the layer has a low velocity than that of MORB and gabbro. However, guided waves have dominant frequencies of 2 to $4 \mathrm{~Hz}$. Therefore, they likely represent subducting crust with thicknesses of about $7 \mathrm{~km}$ rather than sedimentary layers with thicknesses of 0.5 km (e.g., Martin et al. 2003; Abers 2005).

Shiina et al. (2013) showed the existence of free water in the crust at depths of 60 to $90 \mathrm{~km}$ beneath northeastern Japan, which is consistent with depths of dehydration reactions of hydrous minerals (Abers et al. 2013) and concentrated seismicity in the crust (Kita et al. 2006). Although the obtained velocity at the eastern part of Hokkaido was slightly higher than that in northeastern Japan (Figure 7b), which may be associated with the apparent high velocity due to faultinduced anisotropy, the value is still lower than that expected for hydrated compositions of the crust even with anisotropy of $2 \%$ to $3 \%$ (Fujimoto et al. 2010). Therefore, we consider that free water co-exists with hydrous minerals in the crust in eastern Hokkaido. The observed Pwave velocity is reduced by an average of $7 \%$ from the MORB model, and the $S$-wave velocity reduction from the MORB model $(4.1 \mathrm{~km} / \mathrm{s}$; Hacker et al. 2003) is calculated to be approximately $15 \%$, assuming that $V \mathrm{p} / V \mathrm{~s}$ in the subducting crust is 1.90 (e.g., Tsuji et al. 2008). Based on the research of Takei (2002), the obtained P-wave velocity can be explained by fluid fractions of $<1$ vol.\% in the crust with equivalent aspect ratios of 0.01 .

\section{Conclusion}

A clear later phase was observed in seismograms in the western side of the Hidaka Mountain range, the origin

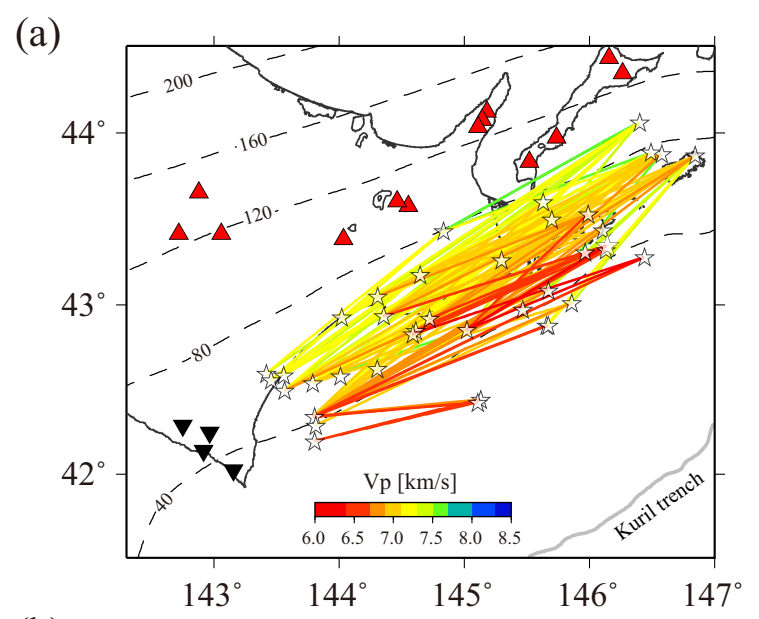

(b)

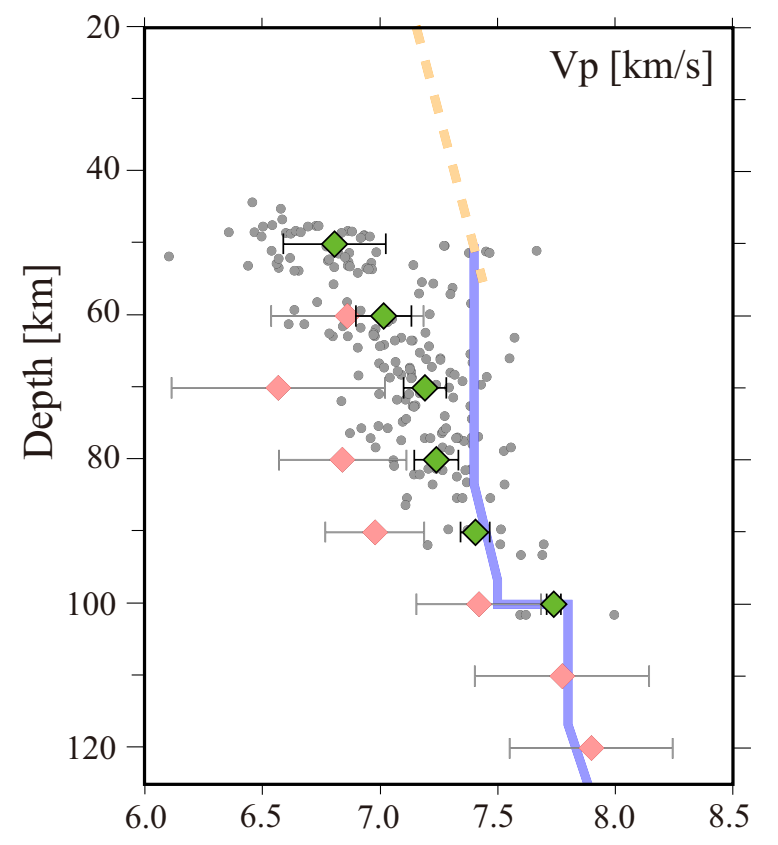

Figure 7 P-wave velocity in the subducting crust beneath the eastern part of Hokkaido. (a) Colored lines show path-averaged P-wave velocity. Hypocenters are plotted as stars. The other symbols are the same as those in Figure 1a. (b) Depth profile of P-wave velocity in the crust. Gray dots are plotted for velocity (horizontal axis) and averaged depth (vertical axis) for pairs of earthquakes. Green diamonds represent the averaged velocity at every $10-\mathrm{km}$ depth slice. Pink diamonds indicate P-wave velocity in the crust beneath northeastern Japan (Shiina et al. 2013). Blue and orange lines show isotropic P-wave velocity expected for a metamorphosed mid-ocean ridge basalt (MORB) model (Hacker et al. 2003) in northeastern Japan and those experimentally derived from lawsonite blueschist (Fujimoto et al. 2010), respectively.

of which we determined through numerical modeling. From the obtained observations and results of numerical simulations, we interpreted the later phase as a guided $\mathrm{P}$ wave generated in the low-velocity subducting 
crust. The efficient energy leakage from the crust provides important evidence for the subducting crust being in contact with the overlying low-velocity material beneath the Hidaka Mountain range. The average P-wave velocities estimated from the travel times of the guided waves were 6.8 to $7.5 \mathrm{~km} / \mathrm{s}$ at depths of 50 to $80 \mathrm{~km}$, suggesting that hydrous minerals are involved in the subducting crust at depths of at least $80 \mathrm{~km}$ beneath the eastern part of Hokkaido.

\section{Competing interests}

The authors declare that they have no competing interests.

\section{Authors' contributions}

TS and JN drafted the manuscript. GT participated in the design of the study and performed the statistical analysis. TM conceived of the study and participated in its design and coordination. All authors read and approved the final manuscript.

\section{Acknowledgements}

We thank the editor Bruno Reynard and two anonymous reviewers for the thoughtful reviews. We used waveform data observed at a nationwide seismograph network; the arrival time, data, and hypocenter were obtained from the unified catalog of the Japan Meteorological Agency. We thank S. Kita for the fruitful discussions. This work was supported by the Ministry of Education, Culture, Sports, Science and Technology of Japan, under its Observation and Research Program for Prediction of Earthquakes and Volcanic Eruptions. All of the figures in this paper were generated by using the GMT software of Wessel and Smith (1998).

Received: 14 December 2013 Accepted: 30 June 2014

Published: 11 July 2014

\section{References}

Abers GA (2005) Seismic low-velocity layer at the top of subducting slabs: observations, predictions, and systematics. Phys Earth Planet Inter 149:7-29, doi:10.1016/j.pepi.2004.10.002

Abers GA, Plank T, Hacker BR (2003) The wet Nicaraguan slab. Geophys Res Lett 30(2):1098, doi:10.1029/2002GRL015649

Abers GA, Nakajima J, van Keken PE, Kita S, Hacker BR (2013) Thermal-petrological controls on the location of earthquakes within subducting plates. Earth Planet Sci Lett 369-370:178-187, doi:10.1016/j.epsl.2013.03.022

Faccenda M, Burlini L, Gerya TV, Maniprice D (2008) Fault-induced seismic anisotropy by hydration in subducting oceanic crust. Nature 455:1097-1100

Ferris A, Abers GA, Christensen DH, Veenstra E (2003) High resolution image of the subducted Pacific (?) plate beneath central Alaska, 50-150 km depth. Earth Planet Sci Lett 214:576-588, doi:10.1016/50012-821X(03)00403-5

Fujimoto Y, Kono Y, Hirajima T, Kanagawa K, Ishikawa M, Arima M (2010) P-wave velocity and anisotropy of lawsonite and epidote blueschists: constraints on water transportation along subducting oceanic crust. Phys Earth Planet Inter 183:219-228, doi:10.1016/j.pepi.2010.09.003

Furumura T, Kennett BLN (2005) Subduction zone guided waves and the heterogeneity structure of the subducted plate: intensity anomalies in northern Japan. J Geophys Res 110, B10302, doi:10.1029/2004JB003486

Furumura T, Moriya T (1990) Three-dimensional Q structure in and around Hidaka Mountains, Hokkaido, Japan. Zishin II 43:121-132 (in Japanese with English abstract)

Garth T, Rietbrock A (2014) Order of magnitude increase in subducted $\mathrm{H}_{2} \mathrm{O}$ due to hydrated normal faults within the Wadati-Benioff zone. Geology G34730:1, doi:10.1130/G34730.1

Hacker BR, Abers GA, Peacock SM (2003) Subduction factory 1. Theoretical mineralogy, densities, seismic wave speeds, and H2O contents. J Geophys Res 108(B1):2029

Hori S, Inoue H, Fukao Y, Ukawa M (1985) Seismic detection of the untransformed 'basaltic' oceanic crust subducting into the mantle. Geophys J R Astron Soc 83:169-197

Horleston AC, Helffrich GR (2012) Constraining sediment subduction: a converted phase study of the Aleutians and Marianas. Earth Planet Sci Lett 359-360:141-151, doi:10.1016/j.epsl.2012.10.019
Iwasaki T, Adachi K, Moriya T, Miyamachi H, Matsushima T, Miyashita K, Takeda T, Taira T, Yamada T, Ohtake K (2004) Upper and middle crustal deformation of an arc-arc collision across Hokkaido, Japan, inferred from seismic refraction/ wide-angle reflection experiments. Tectonophysics 388:59-73

Katsumata A (2010) Depth of the Moho discontinuity beneath the Japanese islands estimated by travel time analysis. J Geophys Res 115, B04303, doi:10.1029/2008JB005864

Kawakatsu H, Watada S (2007) Seismic evidence for deep-water transportation in the mantle. Science 316:1468-1471, doi:10.1126/science.1140855

Kimura G (1996) Collision orogeny at arc-arc junctions in the Japanese Islands. Is| Arc 5:262-275, doi:10.1111/j.1440-1738.1996.tb00031.x

Kirby S, Engdahl ER, Denlinger R (1996) Intermediate-depth intraslab earthquakes and arc volcanism as physical expressions of crustal and uppermost mantle metamorphism in subducting slabs. Geophys Monogr 96:195-214

Kita S, Okada T, Nakajima J, Matsuzawa T, Hasegawa A (2006) Existence of a seismic belt in the upper plane of the double seismic zone extending in the along-arc direction at depths of 70-100 km beneath NE Japan. Geophys Res Lett 33:L24310, doi:10.1029/2006GL028239

Kita S, Okada T, Hasegawa A, Nakajima J, Matsuzawa T (2010) Anomalous deepening of a seismic belt in the upper-plane of the double seismic zone in the Pacific slab beneath the Hokkaido corner: possible evidence for thermal shielding caused by subducted forearc crust materials. Earth Planet Sci Lett 290:415-426, doi:10.1016/j.epsl.2009.12.038

Kita S, Hasegawa A, Nakajima J, Okada T, Matsuzawa T, Katsumata K (2012) High-resolution seismic velocity structure beneath the Hokkaido corner, northern Japan: arc-arc collision and origins of the 1970 M 6.7 Hidaka and 1982 M 7.1 Urakawa-oki earthquakes. J Geophys Res 171:B12301

Martin S, Rietbrock A (2006) Guided waves at subduction zones: dependencies on slab geometry, receiver locations and earthquakes sources. Geophys J Int 167:693-704, doi:10.1111/j.1365-246X.2006.02963.x

Martin S, Rietbrock A, Haberland C, Asch G (2003) Guided waves propagating in subducted oceanic crust. J Geophys Res 108(B11):2536, doi:10.1029/2003JB002450

Martin S, Haberland C, Rietbrock A (2005) Forearc decoupling of guided waves in the Chile-Peru subduction zone. Geophys Res Lett 32, L23309, doi:10.1029/2005GL024183

Matsuzawa T, Ummino N, Hasegawa A, Takagi A (1986) Upper mantle velocity structure estimated from PS-converted wave beneath the north-eastern Japan arc. Geophys J R Astron Soc 86:767-787, doi:10.1111/j.1365-246X.1986. tb000659.X

Miyoshi T, Saito T, Shiomi K (2012) Waveguide effects within the Philippine Sea slab beneath southwest Japan inferred from guided SP converted wave. Geophys J Int 189:1075-1084, doi:10.1111/j.1365-246X.2012.05409.X

Nakajima J, Tsuji Y, Hasegawa A (2009a) Seismic evidence for thermally-controlled dehydration reaction in subducting oceanic crust. Geophys Res Lett 36, L03303, doi:10.1029/2008GL036865

Nakajima J, Hirose F, Hasegawa A (2009b) Seismotectonics beneath the Tokyo metropolitan area, Japan: effect of slab-slab contact and overlap on seismicity. J Geophys Res 114, B08309, doi:10.1029/2008JB006101

Nakajima J, Hada S, Hayami E, Uchida N, Hasegawa A, Yoshioka T, Matsuzawa T, Umino N (2013) Seismic attenuation beneath northeastern Japan: constraints on mantle dynamics and arc magmatism. J Geophys Res Solid Earth doi:10.1002/2013JB010388

Ohkura T (2000) Structure of the upper part of the Philippine Sea plate estimated by later phases of upper mantle earthquakes in and around Shikoku, Japan. Tectonophysics 321:17-36

Reynard B, Bass JD (2014) Elasticity of lawsonite and seismological signature of metamorphism and water cycling in the subducting oceanic crust. J Metamorphic Geol 32:479-487, doi:10.1111/jmg.12072

Shiina T, Nakajima J, Matsuzawa T (2013) Seismic evidence for high pore pressures in the oceanic crust: implications for fluid-related embrittlement. Geophys Res Lett 40:2006-2010, doi:10.1002/grl.50468

Shimizu N, Maeda I (1980) Analysis of seismic waves with the remarkable phases observed at station KMU. Zishin II 33:141-155 (in Japanese with English abstract)

Takei Y (2002) Effect of pore geometry on Vp/Ns: from equilibrium geometry to crack. J Geophys Res 170(B2):2043, doi:10.1029/2001JB000522

Tsuji Y, Nakajima J, Hasegawa A (2008) Tomographic evidence for hydrated oceanic crust of the Pacific slab beneath northeastern Japan: implications for water transportation in subduction zones. Geophys Res Lett 35, L14308, doi:10.1029/2008GL034461 
Ueno H, Hatakeyama S, Aketagawa T, Funasaki J, Hamada N (2002) Improvement of hypocenter determination procedures in the Japan Meteorological Agency. Q J Seismol 65:123-134 (in Japanese)

Virieux J (1986) P-SV wave propagation in heterogeneous media: velocity-stress finite difference method. Geophys J Int 152:649-668

Wessel P, Smith WHF (1998) New, improved version of generic mapping tools released. EOS Trans Am Geophys Un 79:579

doi:10.1186/1880-5981-66-69

Cite this article as: Shiina et al: Guided wave observations and evidence

for the low-velocity subducting crust beneath Hokkaido, northern

Japan. Earth, Planets and Space 2014 66:69.

\section{Submit your manuscript to a SpringerOpen ${ }^{\circ}$} journal and benefit from:

- Convenient online submission

- Rigorous peer review

- Immediate publication on acceptance

- Open access: articles freely available online

- High visibility within the field

- Retaining the copyright to your article

Submit your next manuscript at $\boldsymbol{\wedge}$ springeropen.com 